\title{
Characterization of ex vivo cultured neuronal- and glial- like cells from human idiopathic epiretinal membranes
}

\author{
Sofija Andjelić ${ }^{1 \dagger}$, Xhevat Lumi ${ }^{1 \dagger}$, Xiaohe Yan ${ }^{2}$, Jochen Graw ${ }^{2}$, Morten C Moe ${ }^{3}$, Andrea Facskó ${ }^{4}$, Marko Hawlina ${ }^{1}$ \\ and Goran Petrovski ${ }^{1,4,5^{*}}$
}

\begin{abstract}
Background: Characterization of the neuro-glial profile of cells growing out of human idiopathic epiretinal membranes (iERMs) and testing their proliferative and pluripotent properties ex vivo is needed to better understand the pathogenesis of their formation.

Methods: iERMs obtained during uneventful vitrectomies were cultivated ex vivo under adherent conditions and assessed by standard morphological and immunocytochemical methods. The intracellular calcium dynamics of the outgrowing cells was assessed by fluorescent dye Fura-2 in response to acetylcholine (ACh)- or mechano- stimulation.

Results: The cells from the iERMs formed sphere-like structures when cultured ex vivo. The diameter of the spheres increased by $5 \%$ at day 6 and kept an increasing tendency over a month time. The outgrowing cells from the iERM spheres had mainly glial- and some neuronal- like morphology. ACh- or mechano- stimulation of these cells induced intracellular calcium propagation in both cell types; in the neuronal-like cells resembling action potential from the soma to the dendrites. Immunocytochemistry confirmed presence of glial- and neuronal cell phenotype (GFAP and Nestin-1 positivity, respectively) in the iERMs, as well as presence of pluripotency marker (Sox2).

Conclusion: iERMs contain cells of neuronal- and glial- like origin which have proliferative and pluripotent potential, show functionality reflected through calcium dynamics upon ACh and mechano- stimulation, and a corresponding molecular phenotype.
\end{abstract}

Keywords: Idiopathic epiretinal membrane, Glial- and neuronal cell growth, Pluripotency, Calcium dynamics, Acetylcholine, Mechanostimulation, GFAP, Nestin-1, Sox2, Pax2

\section{Background}

Epiretinal membranes (ERMs) are collections of cells and extracellular matrix that occur on the vitreoretinal interface of the central retina and are laid upon the inner limiting membrane (ILM). They have contractile properties and can lead to visual disturbance and metamorphopsia (distorted vision) due to their tractional effect on the underlying retina. The membranes comprise of glial cells, retinal pigment epithelial (RPE) cells,

\footnotetext{
* Correspondence: petrovski.goran@med.u-szeged.hu

${ }^{\dagger}$ Equal contributors

'Eye Hospital, University Medical Centre, Grablovičeva ulica 46, 1000 Ljubljana, Slovenia

${ }^{4}$ Department of Ophthalmology, Faculty of Medicine, University of Szeged,

Korányi fasor 10-11, 6720 Szeged, Hungary

Full list of author information is available at the end of the article
}

macrophages, fibrocytes and collagen found in varying proportions in accordance with their etiology. Idiopathic epiretinal membranes (iERMs) occur without any association with disease or disease history and are among the most common types of ERMs [1]. Cells of glial origin predominate in the iERMs [2].

It is thought that the iERMs form initially as a result of cell migration (RPE and glial cells such as Müller cells and astrocytes) from within the retina. These cells can either migrate through a hole or tear in the retina onto its surface, as is generally assumed to be the case for RPE cells, or they can simply extend processes out of the retina, as is the case for glial cells $[1,2]$. Once the scaffold for their growth has been formed or the existing ILM has been populated by the migrating cells, other 
cell types present at the vitreoretinal interface, such as hyalocytes - the cells of the vitreous body, and macrophages may come into the picture [3]. Cell contact and attachment to the retina can cause proliferation and formation of sheets of membranes over its surface [2].

Little is known about the presence of neuronal-like cells and their function in human iERMs. Determining the exact cell types found in the membranes has been the focus of several previous studies [4-9]. Using light or electron microscopy, it has been shown that many cells seem to change their morphological characteristics as the ERMs develop, making it difficult to identify their origin [5-8]. In earlier studies [5,10,11], such cells were identified as myofibroblasts, hyalocytes, fibrous astrocytes, RPE, and macrophages using only morphology as the only means for identification. With the addition of immunocytochemistry, however, it has become apparent that the most abundant cell types found in the membranes are glia, macrophages, RPE cells, and fibroblasts $[7,9,12,13]$.

Previously, no reports of ex vivo culturing of cells coming out of iERMs and their functional and molecular characterization have been described. Most of the published studies present a microscopic observation of cells found in the structure of ERMs. We postulate that transdifferentiation of cells involved in the process of ERM formation might be more frequent. We have taken iERM material confirmed by clinical examination and optical coherence tomography (OCT), and cultivated it under adherent conditions. The proliferation potential and the size of the outgrowing cells or spheres were followed over a period of time. Although neuronal-like cells have not yet been detected directly in ERMs, some evidence exists for presence of Nestin-1 positive neural progenitorlike cells in these membranes [14]. Those studies emphasize the capacity of Müller cells, the predominant retinal glial cells, to express Nestin-1 in response to different acute damage such as experimental retinal detachment [15], and hypothesize that Müller cells are able to re-differentiate into retinal neurons after a neurodegenerative disease [16]. Furthermore, the functionality of the iERM outgrowing cells was hereby studied by assessing intracellular calcium $\left[\mathrm{Ca}^{2+}\right]_{\mathrm{i}}$ dynamics upon acetylcholine (ACh)- or mechano- stimulation; such changes play an important role in the regulation of cell function and affect every aspect of the cells' life and death [17].

\section{Methods}

\section{Ethics statement}

All tissue collection complied with the guidelines of the Helsinki Declaration and was approved by the National Medical Ethics Committee of Slovenia. Patients' anonymity and informed consent were provided in each case.

\section{Patient selection}

A case-series study was performed on ten (10) patients in which vitrectomy was carried out due to presence of iERM as confirmed by OCT. The indication for surgery was a decline of visual acuity (VA $<0.5$ on Snellen charts) or better VA in cases when symptomatic metamorphopsia affected the daily activities. Surgeries were performed between May, 2012 and April, 2013 at the Eye Hospital, University Medical Centre Ljubljana, Slovenia. Only patients with IERM were included, and those with secondary or non-idiopathic ERM, as well as diabetic retinopathy, glaucoma, corneal scars, patients after rhegmatogenous retinal detachment, cataract and any other ocular conditions affecting the VA were excluded. Assessment of the VA, slit lamp biomicroscopy and fundus examination by indirect ophthalmoscopy was performed in each patient pre-operatively, and up to 6 month post-operatively. The patient history included age, sex, side of the eye to be operated (right or left eye). Using the Lens Opacities Classification System III classification, patients classified as having nuclear opacities were excluded, if the nuclear opalescence was grade $\geq 2.5$.

Time-domain OCT imaging (3D OCT 1000 Topcon, Japan) was performed in all cases and at each visit. Central Foveal Thickness (CFT) and Total Macular Volume (TMV) were recorded pre-operatively on the surgery day, on the first post-operative day and 3 months postoperatively.

Patients were examined post-operatively at day 1,2 and 3, 1 week, 1 month and 6 months after the surgery.The best corrected VA and intraocular pressure were measured at each visit.

\section{Tissue collection and growth analysis}

iERMs were removed en-block using endgripping forceps. Immediately after removing, the excised tissue was placed into sterile microtubes filled with (Balanced Salt Solution +) BSS+. At the end of surgery, a $360^{\circ}$ inspection of the peripheral retina was performed by scleral depression and the vitreous cavity filled with BSS+. In the case of any peripheral retinal break, an endolaser retinopexy and air tamponade were performed. One part of the iERMs was cultivated ex vivo under adherent conditions in high glucose medium (DMEM, Sigma, No. 5671) supplemented with $10 \%$ fetal bovine serum (FBS). The size and the shape of the outgrowing cells (area of outgrowth) from the sphere-shaped iERMs were recorded and followed on a daily basis up to 8 days and throughout their continued growth for more than 3 months after the isolation.

\section{Immunohistochemical analysis of the iERMs}

The remaining part from each isolated iERM underwent immunohistochemical analysis. In brief, the surgically 
removed iERMs were placed immediately in $4 \%$ paraformaldehyde for at least 24 hours. Then iERMs were washed in PBS/0.1\% TritonX-100 (PBST) two times, and penetrated in $0.1 \mathrm{M}$ Glycin/PBS. After washing in PBST, iERMs were incubated in primary antibody (rabbit GFAP, 1:500, Cat.No.9269 (Sigma-Aldrich, Germany); mouse Nestin, 1:500, Cat.No.561230 (BD Pharmingen, Germany); rabbit Pax2, 1:200, Cat. No.2549-1 (Epitomics, Germany); goat Sox2, 1:500, Cat.No.sc-17320 (Santa Cruz, Germany); rabbit Ki-67, 1:1000, Cat.No.6013874 (Novocastra, Germany); mouse CRALBP, 1:500, Cat.No.sc-376082 (Saanta Cruz, Germany)) or blocking solution (Control) for 24 hours at $4{ }^{\circ} \mathrm{C}$, followed by washing and incubation with secondary antibodies (rabbit Alexa Fluor ${ }^{\circ} 488,1: 250$, Cat.No.A21206 (Invitrogen, Germany); goat Cy3, 1:250, Cat.No. 705-165-147 (Dianova, Germany); mouse Cy5, 1:250, Cat.No.715-175-150 (Jackson Immuno, Germany)) for 1 hour at room temperature. The samples were then incubated in DAPI for 20 minutes and placed on the slides with mounting medium. All the immunofluorescence pictures (single plane images and Z-stacks) were taken by Olympus confocal microscopy (Olympus, Hamburg, Germany) and analyzed by a FluoView software (Olympus). Below is a list of all antibodies used and their dilution.

\section{Calcium dynamics measurement in iERM outgrowing cells}

At day 8, the cultures were loaded with acetoxymethyl (AM) ester of Fura-2 (Fura-2 AM; Invitrogen - Molecular Probes, Carlsbad, CA, USA), a free cytosolic calcium $\left(\mathrm{Ca}^{2+}\right)$ sensitive dye which was dissolved in DMSO and suspended in $1.5 \mathrm{~mL}$ of culture medium (final working concentration: $8 \mu \mathrm{M})$. The Fura-2 AM loading was carried out at $37 \mathrm{oC}$, $5 \% \mathrm{CO}_{2}$ for $40 \mathrm{~min}$. After loading, the cultures were washed twice for $7 \mathrm{~min}$ with $3 \mathrm{~mL}$ of the physiological saline with (in $\mathrm{mM}$ ): $\mathrm{NaCl}$ (131.8), $\mathrm{KCl}(5), \mathrm{MgCl} 2$ (2), $\mathrm{NaH}_{2} \mathrm{PO}_{4}$ (0.5), $\mathrm{NaHCO}_{3}$ (2), $\mathrm{CaCl}_{2}$ (1.8), HEPES (10), glucose (10)), $\mathrm{pH}$ 7.24. The Petri dish was then mounted onto inverted microscope, Zeiss Axiovert S 100 (Carl Zeiss, AG, Oberkochen, Germany). In order to evoke responses from the cells, an agonist - acetylcholine (ACh; Sigma, USA) was applied in $25 \mu \mathrm{M}$ concentration and diluted in physiological saline. The global application of $\mathrm{ACh}$ as well as its washout from the bath was driven simply by the hydrostatic pressure of a $35 \mathrm{~cm}$ water column and controlled manually by a Luer-lock stopcock (WPI) and applied through a polyethylene plastic tubing (inner diameter $2 \mathrm{~mm}$ ) attached to the coarse micromanipulator. The excess bathing solution was removed by a suction line. To additionally test a response to mechanical stimuli, such stimulation was carried out with a tip of a glass micropipette mounted on a MP-285 micromanipulator (Sutter, Novato, CA, USA) was used. Image acquisition was done with the 12-bit cooled CCD camera SensiCam (PCO Imaging AG, Kelheim, Germany). The software used for the acquisition was WinFluor (written by J. Dempster, University of Strathclyde, Glasgow, UK). Microscope objectives used were: 10x/ 0.30 PlanNeoFluar and $63 \mathrm{x} / 1.25$ oil Plan-NeoFluar (Zeiss). The light source used was XBO-75 W (Zeiss) Xe arc lamp. The excitation filters used, mounted on a Lambda LS10 filter wheel (Sutter Instruments Co.) were 360 and $380 \mathrm{~nm}$ (Chroma). Excitation with the $360 \mathrm{~nm}$ filter (close to the Fura-2 isosbestic point) allowed observation of the cells' morphology and of the changes in the concentration of the dye, irrespective of changes in free cytosolic $\mathrm{Ca}^{2+}$ concentrations $\left(\left[\mathrm{Ca}^{2+}\right]_{\mathrm{i}}\right)$, while the $360380 \mathrm{~nm}$ ratio allowed visualization of the $\left[\mathrm{Ca}^{2+}\right] \mathrm{i}$ changes in the cytoplasm. Image acquisition, timing and filterwheel operation were all controlled by WinFluor software via a PCI6229 interface card (National Instruments, Austin, TX, USA). Individual image frames were acquired every $500 \mathrm{~ms}$ resulting in frame cycles being 1 second long (two wavelengths).

\section{Statistical analyses}

The statistical analysis used was paired Student's t-test (two tailed), which was conducted using SPSS software.

\section{Results}

\section{Pre-operative and post-operative patient data}

The iERMs were diagnosed clinically and by OCT in 10 patients (6 males and 4 females; age: 63 to 78 years (average age: $72.2 \pm 4.2$ years)). Four eyes were phakic and 6 were pseudophakic. Vitrectomy was performed in the right eye in 5 and the left eye in 5 patients.

All patients had reduced VA (0.02 to 0.6 on Snellen charts (mean VA: $0.31 \pm 0.22)$ ) and metamorphopsia preoperatively. In all cases, OCT clearly detected the ERMs without any vitreoretinal traction. CFT was increased in each of the patients and ranged from $371 \mu \mathrm{m}$ to $649 \mu \mathrm{m}$ (mean thickness: $502.7 \pm 81.15 \mu \mathrm{m}$ ). TMV ranged from 8.31 to $11.39 \mathrm{~mm}^{3}$ (mean value: $9.99 \pm 1.10 \mathrm{~mm}^{3}$ ). The surgery was in all cases 23-gauge sutureless vitrectomy. There were no intra-operative or post-operative complications. In some of the patients, immediately after the ERM removal, mild petechial haemorrhages occurred on the retinal surface, which usually were not seen on the first post-operative day. In one patient, at the end of the surgery a peripheral retinal break was noticed for which laser retinopexy and air tamponade were performed. During the 6 months follow-up period the retina remained stable in the later case.

Post-operatively the vision improved in 9 eyes, the VA ranging from 0.1 to 0.7 (mean VA: $0.43 \pm 0.23$ ). One eye (patient) had worse vision after surgery: the VA was reduced from 0.6 pre-operatively to 0.5 post-operatively. The primary reason for the subsequent decrease in VA was the occurrence or progression of nuclear sclerosis of 
the crystalline lens. Post-operatively, the CFT was also reduced in all patients and ranged from 273 to $432 \mu \mathrm{m}$ (mean: $336.2 \pm 46.7 \mu \mathrm{m}$ ). The TMV decreased after surgery and ranged from 7.64 to $8.77 \mathrm{~mm}^{3}$ (average value: $8.16 \pm 3.46 \mathrm{~mm}^{3}$ ). These pre-operative and post-operative differences were statistically significant $(\mathrm{p}<0.05)$.

\section{Growth potential of the iERM outgrowing cells}

The cells from the iERMs formed sphere-like structures when cultured ex vivo. The diameter of the spheres increased significantly by $5 \%$ at day $6(256.6 \pm 90.0 \mu \mathrm{m}$, $\mathrm{p}=0.03$ ) and kept an increasing tendency over a month period. The cells growing out of the spheres had mainly a glial or star-shaped morphology with many processes coming out of the soma, while some had a neuronallike morphology with dendritic- and axonal- like extensions coming out of the soma (Figure 1).

\section{Immunophenotype of the cells found in the iERMs}

The iERMs obtained from surgery were examined for expression of glial-, neuronal- and pluripotency markers. Most of the cells in the explanted iERMs expressed GFAP, while some expressed Sox2 and Nestin-1 (Figure 2). Few of the cells co-expressed GFAP and Sox (Figure 2, middle panel images) and similarly, few of them co-expressed GFAP, Sox2 and Nestin-1 at the same time (Figure 2, lower panel images).

Only a trace amount of the cells expressed Ki-67 (Figure 3). Pax 2 (a developmental marker), was also

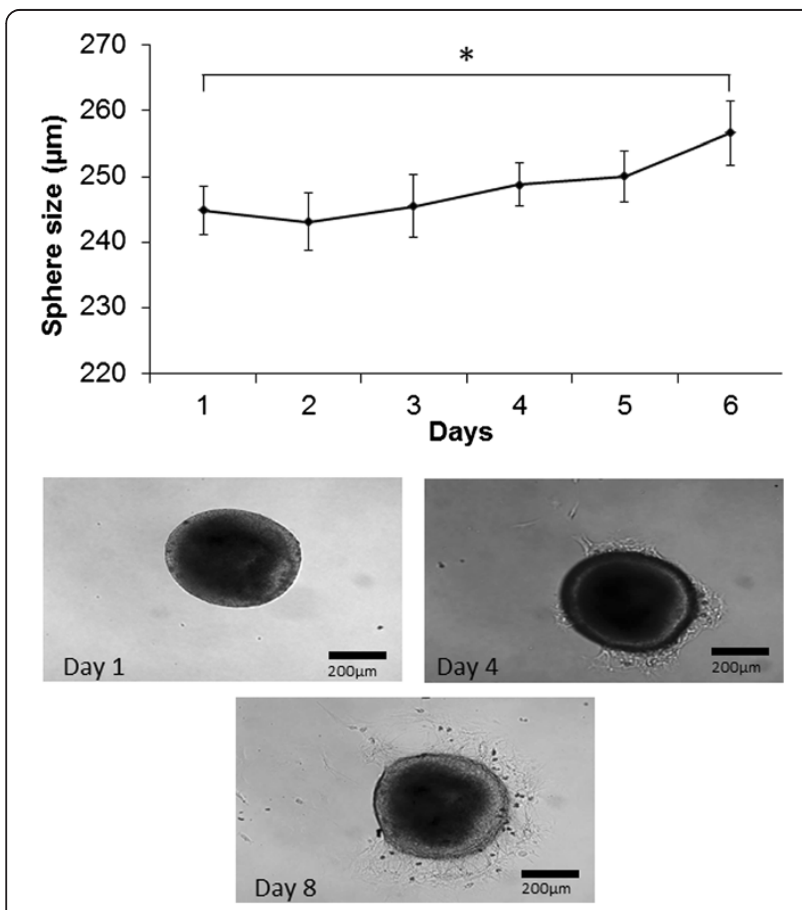

Figure 1 Sphere-like growth of the cultivated iERMs. Data shown are average of four independent experiments $\left({ }^{*} p=0.03\right)$. detected in the iERMs, which was co-expressed with some of the Sox 2 and CRALBP (Müller glial marker) positive cells, respectively (Figure 3 ).

\section{Functionality of the iERM outgrowing cells}

The functionality of the iERM outgrowing cells was assessed by the $\left[\mathrm{Ca}^{2+}\right]_{\mathrm{i}}$ dynamics upon ACh or mechanical stimulation. Some cells derived from the iERM spheres responded to the pharmacological stimulation by $\mathrm{ACh}$ with an increase in $\left[\mathrm{Ca}^{2+}\right]_{i}$, while others showed no change in the $\left[\mathrm{Ca}^{2+}\right]_{i}$. The rise in $\left[\mathrm{Ca}^{2+}\right]_{i}$ was monophasic for the activated cells (Figure 4A,B). The outgrowing cells from the iERM spheres had mainly a glial- and some neuronallike morphology. Stimulation of these cells with ACh induced $\left[\mathrm{Ca}^{2+}\right]_{\mathrm{i}}$ changes in the neuronal-like cells, while not in the glial-like cells (Figure 4A). Upon mechanical stimulation of the single neuronal-like cells with glass micropipette, $\left[\mathrm{Ca}^{2+}\right]_{\mathrm{i}}$ propagation could be observed from the cell body to the dendrites, resembling action potential (Figure 4B).

The cell morphology, as assessed by observation of $360 \mathrm{~nm}$ fluorescencent images, is shown on Figure 4A for the group of cells derived from the sphere of one patient, and for the single cells derived from the sphere of another patient (Figure 4B). The regions of interest (ROIs) are superimposed on the images of morphology, and are presented in different colors which correspond to the traces showing the time courses of the 360380 ratio, proportional to $\left[\mathrm{Ca}^{2+}\right]_{\mathrm{i}}$ for the selected ROIs. The resting levels, the increase in 360/380 ratio upon stimulation and the amplitudes of the ratio of the responses, corresponding to the resting levels and the changes in $\left[\mathrm{Ca}^{2+}\right]_{\mathrm{i}}$ can be seen in Figure 4 .

\section{Discussion}

A case-series study of 10 patients with iERM is presented in which immunohistochemical and functional evidence of their ex vivo proliferative and pluripotency potential is shown. Apart from that, clinical data showing similar postoperative outcomes of VA and OCT changes to other previously published data are presented in support of the successful procedures carried [18-20].

To date, the pathogenesis of ERMs is not fully clear. The two main cellular components of the ERMs are cells of retinal and extra-retinal origin, as well as extracellular matrix (consisting of collagen, laminin, tenascin, fibronectin, vitronectin and thrombospondin) $[9,21]$. The origin of the cells which contribute to ERM formation has not been fully understood. Hiscot et al. identified oval cells, spindle-shaped cells, and cuboidal cells in ERMs, which stained positively for epithelial markers [4]. Further histological and immunohistochemical analysis has shown that cells involved in ERM formation are RPE metaplastic cells, glial cells (Müller cells and astrocytes), 


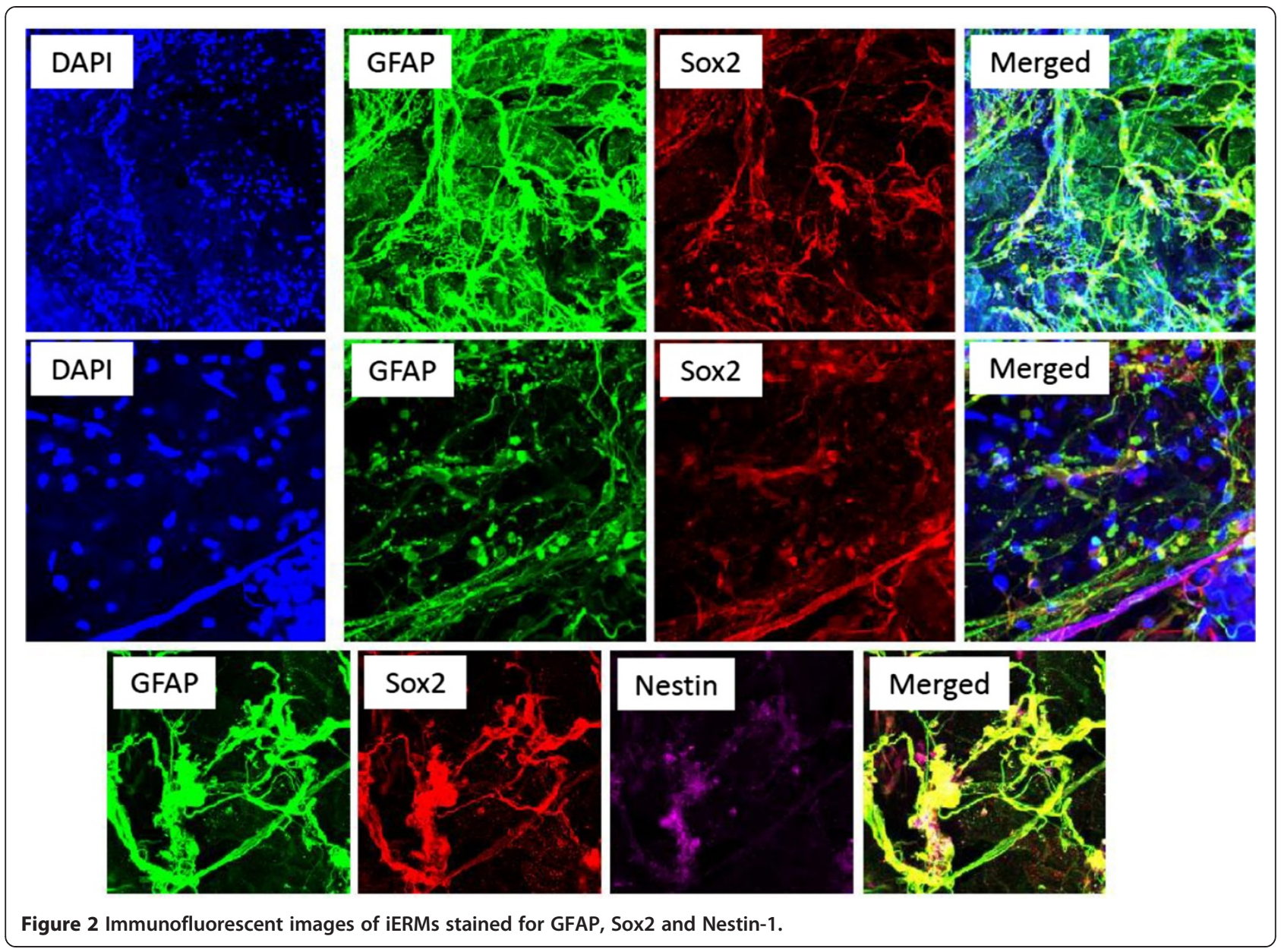

hyalocytes, endothelial cells, fibroblasts, myofibroblasts, monocytes, and macrophages [7,22]. Zhao et al. stated that hyalocytes constitute a major cell type of the epiretinal cell proliferation in eyes with macular pucker and vitreomacular traction syndrome. In the membranes, they noticed myofibroblast-like cells, being immunoreactive for $\alpha$-SMA and of unknown origin, representing contractile elements of epiretinal tissue possibly as a consequence of cellular transdifferentiation [23].

The only cellular components of the ERMs in a series studied by Snead et al. were $\mathrm{GFAP}^{+}$and $\mathrm{AE} 1 / \mathrm{AE}^{+}$cells. They preferred to name these cells laminocytes as a term for glial cells, glial fibroblasts, astrocytic cells, and Muller cells [24]. Lewis et al. found the proof of neurite growth in
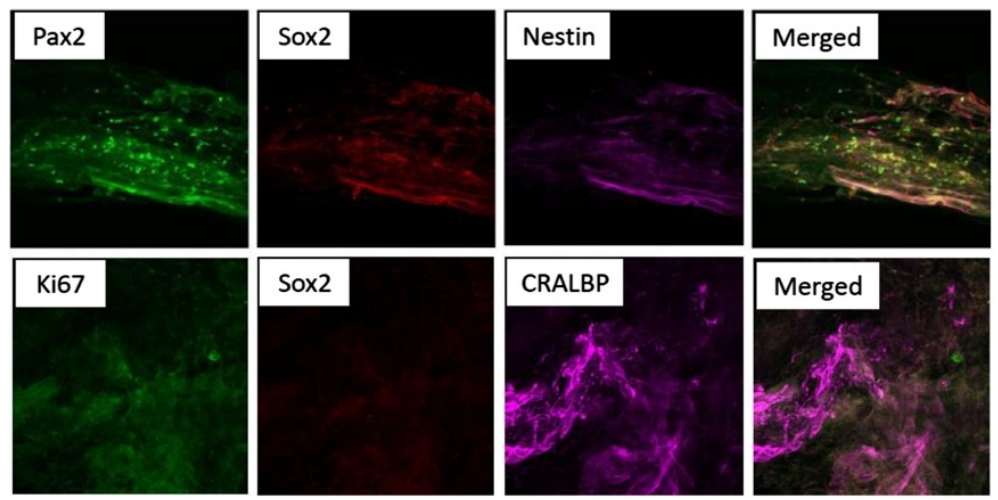

Figure 3 Immunofluorescent images of iERMs stained for Pax2, Sox2 and Nestin-1. (Cellular retinaldehyde-binding protein (CRALBP) serves as a marker for Müller glial cells of the retina). 


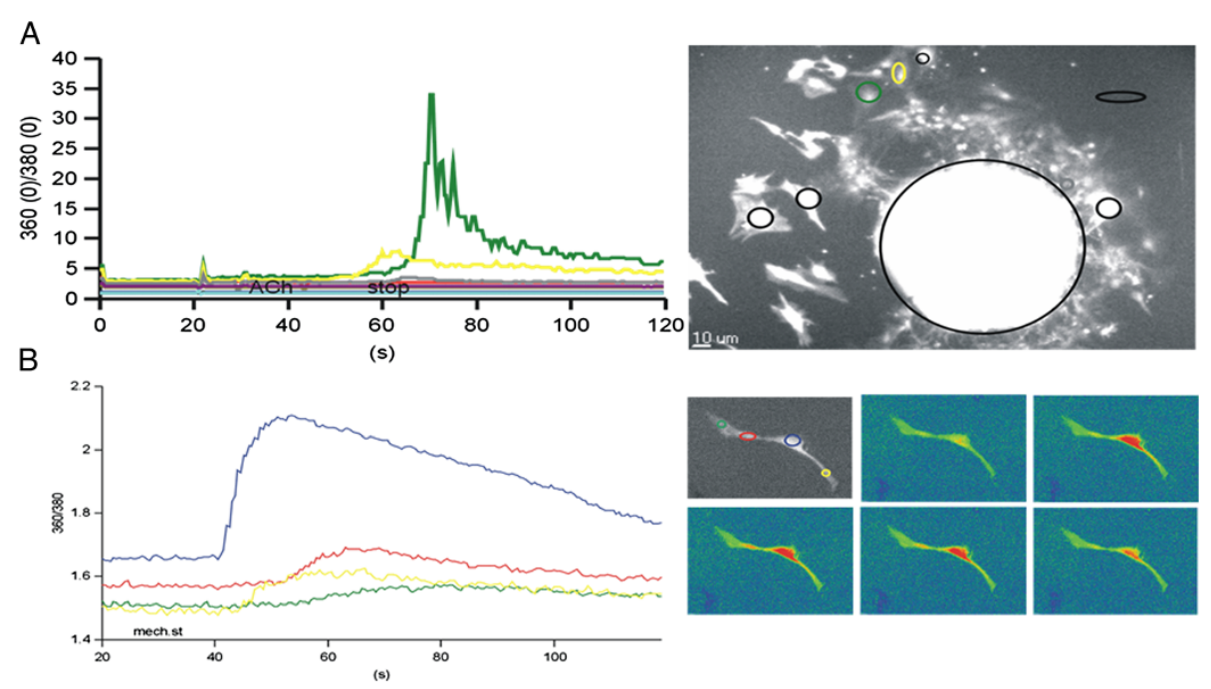

Figure 4 Calcium dynamics in the neuronal-like cells derived from an iERM upon different stimulation. $\left[\mathrm{Ca}^{2+}\right]_{\mathrm{i}}$, responses upon acetylcholine (ACh) (A) and mechano- stimulation (B).

ERMs since $100 \%$ of the samples contained neurofilament labelled processes [25].

Electron microscopy and immunocytochemical studies have shown changes of the morphological characteristics of cells during ERM development, but it was difficult to distinguish the origin of these cells from morphological studies only [6-8]. The outgrowth of Müller cell processes onto the inner retinal surface has been considered being the first step in the process of ERM formation $[10,26]$. Schubert et al. suggested that under normal conditions many vitreous fibers distribute tractional forces to numerous Müller cell attachments. However, in cases of partial posterior vitreous detachment (PVD), fewer vitreous fibers and Müller cells endure most of the traction, which may result in a chronic irritation of Müller cells. PVD and chronic irritation of Müller cells can facilitate a local release of factors that, in turn, can induce Müller cell gliosis and vascular leakage [27]. General signs of Müller cell gliosis are cellular hypertrophy and upregulation of the intermediate filaments vimentin and GFAP, followed by transient or long lasting proliferation of these cells [12]. GFAP expression in simple ERMs demonstrates that the majority of the cells involved in the membrane formation derive from glial cells [13]. Within the membranes, glial and pigment epithelial cells may transdifferentiate to other cells, e.g. contractile myofibrocytes, which is characterized by a reduction in cell-specific proteins such as GFAP and cytokeratins [28,29].

In their immunocytochemistry model of ERMs, Oberstein et al. showed the presence of $\mathrm{Ki}-67^{+}$proliferating glial-, ezrin ${ }^{+}$RPE-, GFAP ${ }^{+}$and vimentin ${ }^{+}$glial cells, as well as ricin $^{+}$immune cells in all four types of the ERMs studied, regardless of their duration of occurrence in the eye. According to their findings, there is strong evidence that RPE cells can migrate through the intact retina [3]. These data support the hypothesis that ERM formation is a wound healing process [30].

Bringmann et al. described how Müller cells in proliferative vitreoretinopathy (PVR) can display a distinct potential for transdifferentiation into a progenitor- or neuron-like phenotype [31]. They hypothesized that cellular transdifferentiation may represent one reason for the relatively few glial and pigment epithelial cells being detected in fibrocellular membranes by commonly used immunocytochemical markers. Progenitor cells have been found in tissues which have potential to regenerate and differentiate into various phenotypes. One marker for progenitor cells is Nestin. Mayer et al. found in adult human retina and ERMs removed during retinal surgery Nestinstaining patterns associated with cells of neural and glial morphology. Nestin positive cells in the adult human retina display morphological and geographical similarity to neurons, including retinal ganglion cells, other neurons, and Müller cells. In the ERMs, these cells were found coexpressed with GFAP [14].

In distinction to the histological and immunocytochemical studies published so far, we established a different model for analyzing the proliferative, differentiation, pluripotency and functional potential of the cells isolated from iERMs. The collected iERMs were cultivated ex vivo under adherent conditions in high glucose medium supplemented with $10 \%$ FBS. Cells from the ERM started to form sphere like structures within first few days and kept growing over a month period (the overall follow-up time was 6 months when the ongoing growth was intentionally discontinued). Within the first 6 days, the diameter of the growing spheres increased significantly, the cells showing mainly a glial or star-shaped morphology, while some 
showing neuronal-like morphology, which was clearly reflected by most cells expressing GFAP, and some expressing Nestin-1. In addition, few cells expressed Sox2, while some showed co-expression of Sox2 and Nestin-1. Only a trace amount of the cells expressed the cell proliferation marker Ki-67. Interestingly, Pax2 which is prominently expressed at sites where tissue outgrowth and shaping takes place [32] was expressed in the cells found in iERMs and it was found partially co-expressed with Sox 2 positive cells.

In animal models, it has been shown that small increases in the levels of Sox 2 expression (2-fold or less) could lead to rapid differentiation of epithelial stem cells into cells expressing neuroectodermal, mesodermal and trophectodermal markers [33]. Sox2 is probably one of the proteins which act as molecular rheostat in the control of epithelial stem cell self-renewal and pluripotency [34]. Demonstrating the presence of Sox 2 in the iERMs proved the presence of pluripotency of at least some of the cells growing out of the iERMs. These data are unique in studying the proliferation of iERM cells altogether.

The neuronal-like cells in ERMs have not been found directly, so neither has been their calcium signaling. Nestin being an intermediate filament marker for neural progenitor cells has been shown to exist in ERMs [14], however, other studies have emphasized the capacity of Müller cells, the predominant retinal glial cells, to express Nestin in response to different acute damage paradigms such as experimental retinal detachment [15]. These studies have hypothesized that Müller cells are capable of re-differentiating into retinal neurons after a neurodegenerative disease [16]. The calcium signaling in outgrowing cells can be studied by chemical stimulation following administration of $\mathrm{ACh}$, and mechanical stimulation, both being known to induce calcium signaling in retinal cells [35]. ACh receptors are widely present in the retina and they play important roles in it. Nicotinic ACh receptors, alpha7 nAChR, are expressed in RPE cells [36] and in bipolar, amacrine, and ganglion cells of the rabbit retina [37]. Muscarinic receptors, M1 and $\mathrm{M} 4 \mathrm{mAChR}$, are expressed in retinal ganglion cells [38], and all five $\mathrm{mAChR}$ subtypes are expressed by subpopulations of bipolar, amacrine, and ganglion cells in the rabbit retina [39]. Amacrine cells, which are excitatory cells with an ACh release early in the development of the retina, have been show to require this neurotransmitter for development of retinal waves [40]. The transient cholinergic network plays an important role in the various aspects of retinal development [41]. Control of cell proliferation by neurotransmitters in the developing vertebrate retina also involves ACh [42]. Neuroprotection of rat retinal ganglion cells against glutamate-induced excitotoxicity is mediated through alpha7 nACh receptors [43].
The presence of ACh receptors on iERM cells and the calcium response of these cells to ACh stimulation, to the best of our knowledge, have not been studied before. As iERMs appear to form initially as a result of cells coming from within the retina, and since ACh plays an important role in retinal development, altogether, this suggests a putative role of ACh in the iERM development, which we studied further. Nicotinic ACh receptors have multiple roles in proliferation in cancer in general [44], suggesting they might have a similar role in the proliferation of iERM cells. Recent studies have documented the effect of topical nicotine on improving dermal wounds [45] suggesting it may have roles in wound repair, therefore, possibly cell repair as well. Blocking $n$ - and mAChRs on non-innervated cells causes cellular dysfunction and/or cell death. Embryonic stem cells from mice, epithelial, endothelial and immune cells can all synthesize ACh, which via differently expressed patterns of $n$ - and mAChRs can modulate cell activities to respond to internal or external stimuli. This helps maintain and optimize cell function, such as proliferation, differentiation, formation of a physical barrier, migration, and ion and water movements [46].

Alternatively, when cells are stimulated by mechanical deformation, in particular, when diseases characterized by mechanical stress cause stretching of the RPE cells by the vitreous or hyperplastic membranes' formation as in rhegmatogenous retinal detachment and PVR, the 'on' mechanisms become activated and the cytosolic free $\mathrm{Ca}^{2+}$ concentration increases. The $\mathrm{Ca}^{2+}$ 'on' mechanisms can include channels located at the plasma membrane which can further regulate the inexhaustible supply of $\mathrm{Ca}^{2+}$ from the extracellular space, and channels on the endoplasmic and sarcoplasmic reticulum which release the finite intracellular $\mathrm{Ca}^{2+}$ stores [47]. Mechanical stimulation of iERM cells has not been described so far, although mechanical stimulation of retinal cells has shown changes in the $\left[\mathrm{Ca}^{2+}\right]_{\mathrm{i}}$ levels. Mechanical stimulation of astrocytes of rat retina could initiate an increase in the $\left[\mathrm{Ca}^{2+}\right]_{\mathrm{i}}$ that propagated through astrocytes and Müller cells as intercellular waves. Generation of $\mathrm{Ca}^{2+}$ waves can occur by the release of $\mathrm{Ca}^{2+}$ from internal stores, but the waves do not evoke changes in cell membrane potential. It was suggested that such glial $\mathrm{Ca}^{2+}$ waves may constitute an extraneuronal signaling pathway $[48,49]$. Forces applied to resting primary astrocytes produced a fast transient change of $\left[\mathrm{Ca}_{]_{i}^{2+}}\right.$ adapting within seconds [50]. Furthermore, stimulation of RPE cells with mechanical stress can upregulate matrix metalloproteinases (MMP-2) and fibronectin (FN) expression through activation of the p38 pathway [51].

Elevated intraocular pressure can also trigger a physiological release of ATP from the retina. Stimulation of the purinergic $\mathrm{P}_{2} \mathrm{X}_{7}$ receptor for ATP on retinal ganglion cells can lead to elevation of $\left[\mathrm{Ca}^{2+}\right]_{i}$ and excitotoxic death 
[52]. Isolated retinal ganglion cells can respond directly to mechanical deformation with pannexin-mediated ATP release and autostimulation of $\mathrm{P}_{2} \mathrm{X}_{7}$ receptors [53].

Since calcium signaling can occur in both neuronal and glial cells, calcium imaging cannot be used for discriminating glia cells from neurons [54-56], which can be an obvious limitation of this study. Glial cells can respond to various stimuli with an increase in $\left[\mathrm{Ca}^{2+}\right]_{\mathrm{i}}$, but not by forming action potentials. Mechanical stimulation of astrocyte somata in rat retina could evoke calcium waves that could propagate through both astrocytes and Müller cells [49]. Calcium signaling upon ACh stimulation has been demonstrated in cultured retinal neurons and Müller cells [57]. Forces applied to resting primary astrocytes produce a fast transient change of $\left[\mathrm{Ca}^{2+}\right]_{i}$ adapting within seconds [50]. ACh receptors are known to exist in astrocytes of rat hippocampus and cortex $[58,59]$ and to induce the increase in $\left[\mathrm{Ca}^{2+}\right]_{\mathrm{i}}$.

Overall, the etiology, cellular types and the origin of the cells found in ERMs has been a matter of long-term debate. Investigations searching for cell type-specific markers expressed on ERM cells, in particular coming from iERMs, have not lead to a distinct conclusion about their origin, probably due to phenotypic transdifferentiation and lack of a specific marker for transdifferentiated cells thereof [7]. A majority of the present cells in this study were $\mathrm{GFAP}^{+}$, however some Sox2 $2^{+}$and $\mathrm{Ki}-67^{+}$ cells, as well as $\mathrm{Pax}^{+}$(a putative new marker for cells found in iERMs) could be detected in the studied membranes. Therefore, we postulate that cells found in iERMs have a proliferative and differentiation or transdifferentiation potential [23] based upon their immunocytochemical properties and growth patterns, and the functional studies with chemo- and mechano- stimulation. Further functional studies as well as protein and gene expression studies are needed to find out which ACh receptor types in iERMs are affected by application of different agonists and antagonists, and which one of them can further affect the proliferation and differentiation potential of the ERM cells.

\section{Conclusions}

Outgrowing cells from human iERMs show mainly glialand some neuronal- like phenotype (GFAP and Nestin-1 positivity, respectively), proliferate and express pluripotency potential (Sox2 positivity). ACh- or mechano- stimulation of these cells induces intracellular calcium propagation; in the neuronal-like cells, it resembles action potential from the soma to the dendrites.

\section{Abbreviations}

ACh: Acetylcholine; $\left[\mathrm{Ca}^{2+}\right]$, AM: Acetoxymethyl ester; intracellular calcium; CFT: Central Foveal Thickness; CRALBP: Cellular retinaldehyde-binding protein; FN: Fibronectin; FBS: Fetal bovine serum; GFAP: Glial fibrillary aacidic protein; iERM: Idopathic epiretinal membranes; MMP-2: Matrix metalloproteinase 2;
OCT: Optical coherence tomography; PBST: PBS/0.1\%TritonX-100; PVD: Posterior vitreous detachment; PVR: Proliferative vitreoretinopathy; ROI: Region of interest; RPE: Retinal pigment epithelium; TMV: Total Macular Volume; VA: Visual Acuity.

\section{Competing interests}

The authors declare that they have no competing interests.

\section{Authors' contributions}

SA, XL and GP carried out the isolation and cultivation of cells, XY and MCM carried out imunohistochemical analysis, SA, JG, FA, MH and GP overviewed and validated the results and the analysis, SA and GP performed the calcium dynamics measurements, SA, XL and GP participated in the design of the study. GP conceived of the study, and participated in its design and coordination. All authors read and approved the final manuscript.

\section{Acknowledgements}

The work has been supported by the TÁMOP-4.2.2A-11/1/KONV-2012-0023 Grant, project implemented through the New Hungary Development Plan and cofinanced by the European Social Fund and the Slovenian Research Agency (ARRS) Program P3-0333, and a personal cofinancing grant to Goran Petrovski from ARRS. In addition, support has been obtained from the Research Council of Norway, the Norwegian Association of the Blind and Partially Sighted, Blindemissionen IL, the Faculty of Medicine University of Oslo and Oslo University Hospital. All tissue harvesting used for figure illustrations were approved by the Local Committees for Medical Research Ethics. The authors declare that there is no conflict of interests regarding the publication of this paper. The collection of clinical samples and data were performed in Slovenia and Hungary; cultivation of cells ex vivo was carried out in Hungary and Norway; immunohistochemical analysis was performed in Germany; calcium dynamics measurements were performed in Slovenia. Parts of the paper were presented at the 2013 ARVO Conference in Seattle, USA.

\section{Author details}

${ }^{1}$ Eye Hospital, University Medical Centre, Grablovičeva ulica 46, 1000 Ljubljana, Slovenia. ${ }^{2}$ Helmholtz Center Munich - German Research Center for Environmental Health, Institute of Developmental Genetics, Ingolstaedter Landstr. 1, D-85764 Neuherberg, Germany. ${ }^{3}$ Center for Eye Research, Department of Ophthalmology, Oslo University Hospital and University of Oslo, and Norwegian Center for Stem Cell Research, Kirkeveien 166, 0407 Oslo, Norway. ${ }^{4}$ Department of Ophthalmology, Faculty of Medicine, University of Szeged, Korányi fasor 10-11, 6720 Szeged, Hungary. ${ }^{5}$ Stem Cells and Eye Research Laboratory, Department of Biochemistry and Molecular Biology and Apoptosis and Genomics Research Group of the Hungarian Academy of Sciences, Faculty of Medicine, University of Debrecen, Egyetem tér 1., 4032 Debrecen, Hungary.

Received: 11 October 2014 Accepted: 11 December 2014 Published: 23 December 2014

\section{References}

1. McCarty DJ, Mukesh BN, Chikani V, Wang JJ, Mitchell P, Taylor HR, McCarty CA: Prevalence and associations of epiretinal membranes in the visual impairment project. Am J Ophthalmol 2005, 140:288-294.

2. Oh KT: In Epimacular membrane. Edited by Roy H. Medscape; 2014. http://emedicine.medscape.com/article/1223882-overview

3. Oberstein SY, Byun J, Herrera D, Chapin EA, Fisher SK, Lewis GP: Cell proliferation in human epiretinal membranes: characterization of cell types and correlation with disease condition and duration. Mol Vis 2011, 17:1794-1805.

4. Hiscott PS, Grierson I, McLeod D: Natural history of fibrocellular epiretinal membranes: a quantitative, autoradiographic, and immunohistochemical study. Br J Ophthalmol 1985, 69:810-823.

5. Kampik A, Kenyon KR, Michels RG, Green WR, de la Cruz ZC: Epiretinal and vitreous membranes. Comparative study of 56 cases. Arch Ophthalmol 1981, 99:1445-1454.

6. Morino I, Hiscott P, McKechnie N, Grierson I: Variation in epiretinal membrane components with clinical duration of the proliferative tissue. $\mathrm{Br} J$ Ophthalmol 1990, 74:393-399. 
7. Vinores SA, Campochiaro PA, Conway BP: Ultrastructural and electron-immunocytochemical characterization of cells in epiretinal membranes. Invest Ophthalmol Vis Sci 1990, 31:14-28.

8. Baudouin C, Brignole F, Bayle J, Fredj-Reygrobellet D, Lapalus P, Gastaud P: Class II histocompatibility antigen expression by cellular components of vitreous and subretinal fluid in proliferative vitreoretinopathy. Invest Ophthalmol Vis Sci 1991, 32:2065-2072.

9. Heidenkummer HP, Kampik A: Proliferative activity and immunohistochemical cell differentiation in human epiretinal membranes. Ger J Ophthalmol 1992, 1:170-175.

10. Van Horn DL, Aaberg TM, Machemer R, Fenzl R: Glial cell proliferation in human retinal detachment with massive periretinal proliferation. Am J Ophthalmol 1977, 84:383-393.

11. Machemer R, van Horn D, Aaberg TM: Pigment epithelial proliferation in human retinal detachment with massive periretinal proliferation. Am J Ophthalmol 1978, 85:181-191

12. Heidenkummer HP, Kampik A, Petrovski B: Proliferative activity in epiretinal membranes. The use of the monoclonal antibody Ki-67 in proliferative vitreoretinal diseases. Retina 1992, 12:52-58.

13. Jerdan JA, Pepose JS, Michels RG, Hayashi H, de Bustros S, Sebag M, Glaser BM: Proliferative vitreoretinopathy membranes. An immunohistochemical study. Ophthalmology 1989, 96:801-810.

14. Mayer EJ, Hughes EH, Carter DA, Dick AD: Nestin positive cells in adult human retina and in epiretinal membranes. Br J Ophthalmol 2003, 87:1154-1158.

15. Luna G, Lewis GP, Banna CD, Skalli O, Fisher SK: Expression profiles of nestin and synemin in reactive astrocytes and Muller cells following retinal injury: a comparison with glial fibrillar acidic protein and vimentin. Mol Vis 2010, 16:2511-2523.

16. Valamanesh F, Monnin J, Morand-Villeneuve N, Michel G, Zaher M, Miloudi S, Chemouni D, Jeanny JC, Versaux-Botteri C: Nestin expression in the retina of rats with inherited retinal degeneration. Exp Eye Res 2013, 110:26-34

17. Clapham DE: Calcium signaling. Cell 2007, 131:1047-1058.

18. Hassenstein A: Scholz F and Richard G [OCT in epiretinal gliosis]. Der Ophthalmologe: Zeitschrift der Deutschen Ophthalmologischen Gesellschaft 2005, 102:127-132

19. Ishida M, Takeuchi S, Nakamura M, Morimoto K, Okisaka S: The surgical outcome of vitrectomy for idiopathic epiretinal membranes and foveal thickness before and after surgery. Nippon Ganka Gakkai Zasshi 2004, 108:18-22.

20. Mitamura Y, Hirano K, Baba T, Yamamoto S: Correlation of visual recovery with presence of photoreceptor inner/outer segment junction in optical coherence images after epiretinal membrane surgery. Br J Ophthalmol 2009, 93:171-175.

21. Kritzenberger M, Junglas B, Framme C, Helbig H, Gabel VP, Fuchshofer $R$, Tamm ER, Hillenkamp J: Different collagen types define two types of idiopathic epiretinal membranes. Histopathology 2011, 58:953-965.

22. Zhang X, Barile G, Chang S, Hays A, Pachydaki S, Schiff W, Sparrow J: Apoptosis and cell proliferation in proliferative retinal disorders: PCNA, Ki-67, caspase-3, and PARP expression. Curr Eye Res 2005, 30:395-403.

23. Zhao F, Gandorfer A, Haritoglou C, Scheler R, Schaumberger MM, Kampik A, Schumann RG: Epiretinal cell proliferation in macular pucker and vitreomacular traction syndrome: analysis of flat-mounted internal limiting membrane specimens. Retina 2013, 33:77-88.

24. Snead DR, James S, Snead MP: Pathological changes in the vitreoretinal junction 1: epiretinal membrane formation. Eye 2008, 22:1310-1317.

25. Lewis GP, Betts KE, Sethi CS, Charteris DG, Lesnik-Oberstein SY, Avery RL, Fisher SK: Identification of ganglion cell neurites in human subretinal and epiretinal membranes. Br J Ophthalmol 2007, 91:1234-1238.

26. Fisher SK, Lewis GP: Muller cell and neuronal remodeling in retinal detachment and reattachment and their potential consequences for visual recovery: a review and reconsideration of recent data. Vis Res 2003, 43:887-897.

27. Schubert HD: Cystoid macular edema: the apparent role of mechanical factors. Prog Clin Biol Res 1989, 312:277-291.

28. Guidry C: The role of Muller cells in fibrocontractive retinal disorders. Prog Retin Eye Res 2005, 24:75-86.

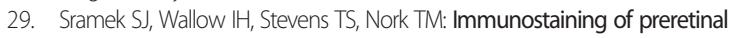
membranes for actin, fibronectin, and glial fibrillary acidic protein. Ophthalmology 1989, 96:835-841.

30. Midwood KS, Williams LV, Schwarzbauer JE: Tissue repair and the dynamics of the extracellular matrix. Int J Biochem Cell Biol 2004, 36:1031-1037.
31. Bringmann A, Wiedemann P: Involvement of Muller glial cells in epiretinal membrane formation. Graefe's archive for clinical and experimental ophthalmology=Albrecht von Graefes Archiv fur klinische und experimentelle Ophthalmologie 2009, 247:865-883.

32. Rajakumar V, Chamberlin HM: The Pax2/5/8 gene egl-38 coordinates organogenesis of the C. elegans egg-laying system. Dev Biol 2007, 301:240-253.

33. Kopp $J L$, Ormsbee BD, Desler M, Rizzino A: Small increases in the level of Sox2 trigger the differentiation of mouse embryonic stem cells. Stem Cells 2008, 26:903-911.

34. Rizzino A: Sox2 and Oct-3/4: a versatile pair of master regulators that orchestrate the self-renewal and pluripotency of embryonic stem cells. Wiley Interdiscip Rev Syst Biol Med 2009, 1:228-236.

35. Ohmasa M, Saito T: Muscarinic calcium mobilization in the regenerating retina of adult newt. Brain Res Dev Brain Res 2003, 145:61-69.

36. Maneu V, Gerona G, Fernandez L, Cuenca N, Lax P: Evidence of alpha 7 nicotinic acetylcholine receptor expression in retinal pigment epithelial cells. Vis Neurosci 2010, 27:139-147.

37. Dmitrieva NA, Strang CE, Keyser KT: Expression of alpha 7 nicotinic acetylcholine receptors by bipolar, amacrine, and ganglion cells of the rabbit retina. The J Histochem Cytochem: Off J Histochem Soc 2007, 55:461-476.

38. Almasieh M, Zhou Y, Kelly ME, Casanova C, Di Polo A: Structural and functional neuroprotection in glaucoma: role of galantamine-mediated activation of muscarinic acetylcholine receptors. Cell Death Dis 2010, 1: e27.

39. Strang CE, Renna JM, Amthor FR, Keyser KT: Muscarinic acetylcholine receptor localization and activation effects on ganglion response properties. Invest Ophthalmol Vis Sci 2010, 51:2778-2789.

40. Ford KJ, Felix AL, Feller MB: Cellular mechanisms underlying spatiotemporal features of cholinergic retinal waves. The J Neurosci: Off J Soc Neurosci 2012, 32:850-863.

41. Ford KJ, Feller MB: Assembly and disassembly of a retinal cholinergic network. Vis Neurosci 2012, 29:61-71.

42. Martins RA, Pearson RA: Control of cell proliferation by neurotransmitters in the developing vertebrate retina. Brain Res 2008, 1192:37-60.

43. Iwamoto K, Mata D, Linn DM, Linn CL: Neuroprotection of rat retinal ganglion cells mediated through alpha7 nicotinic acetylcholine receptors. Neuroscience 2013, 237:184-198.

44. Egleton RD, Brown KC, Dasgupta P: Nicotinic acetylcholine receptors in cancer: multiple roles in proliferation and inhibition of apoptosis. Trends Pharmacol Sci 2008, 29:151-158.

45. Martin JW, Mousa SS, Shaker O, Mousa SA: The multiple faces of nicotine and its implications in tissue and wound repair. Exp Dermatol 2009, 18:497-505

46. Wessler I, Kirkpatrick CJ: Acetylcholine beyond neurons: the non-neuronal cholinergic system in humans. Br J Pharmacol 2008, 154:1558-1571.

47. Bootman MD, Holmes AM, Roderick HL: Calcium signalling and regulation of cell function. In., 24 APR 2006 edn; 2006.

48. Newman EA, Zahs KR: Calcium waves in retinal glial cells. Science 1997, 275:844-847.

49. Newman EA: Propagation of intercellular calcium waves in retinal astrocytes and Muller cells. J Neurosci: Off J Soc Neurosci 2001, 21:2215-2223.

50. Niggel J, Sigurdson W, Sachs F: Mechanically induced calcium movements in astrocytes, bovine aortic endothelial cells and C6 glioma cells. J Membr Biol 2000, 174:121-134.

51. Hou X, Han QH, Hu D, Tian L, Guo CM, Du HJ, Zhang P, Wang YS, Hui YN: Mechanical force enhances MMP-2 activation via p38 signaling pathway in human retinal pigment epithelial cells. Graefe's Arch Clin Exp Ophthalmol = Albrecht von Graefes Archiv fur klinische und experimentelle Ophthalmologie 2009, 247:1477-1486.

52. Reigada D, Lu W, Zhang M, Mitchell CH: Elevated pressure triggers a physiological release of ATP from the retina: Possible role for pannexin hemichannels. Neuroscience 2008, 157:396-404.

53. Xia J, Lim JC, Lu W, Beckel JM, Macarak EJ, Laties AM, Mitchell CH: Neurons respond directly to mechanical deformation with pannexin-mediated ATP release and autostimulation of $\mathrm{P} 2 \mathrm{X} 7$ receptors. J Physiol 2012, 590:2285-2304.

54. Verkhratsky A, Rodriguez JJ, Parpura V: Calcium signalling in astroglia. Mol Cell Endocrinol 2012, 353:45-56

55. Deitmer JW, Verkhratsky AJ, Lohr C: Calcium signalling in glial cells. Cell Calcium 1998, 24:405-416. 
56. Laskey AD, Roth BJ, Simpson PB, Russell JT: Images of Ca2+ flux in astrocytes: evidence for spatially distinct sites of $\mathrm{Ca} 2+$ release and uptake. Cell Calcium 1998, 23:423-432.

57. Wakakura M, Utsunomiya-Kawasaki I, Ishikawa S: Rapid increase in cytosolic calcium ion concentration mediated by acetylcholine receptors in cultured retinal neurons and Muller cells. Graefe's Arch Clin Exp Ophthalmol = Albrecht von Graefes Archiv fur klinische und experimentelle Ophthalmologie 1998, 236:934-939.

58. Shen JX, Yakel JL: Functional alpha7 nicotinic ACh receptors on astrocytes in rat hippocampal CA1 slices. J Mol Neurosci: MN 2012, 48:14-21.

59. Ferroni S, Marchini C, Ogata T, Schubert P: Recovery of deficient cholinergic calcium signaling by adenosine in cultured rat cortical astrocytes. J Neurosci Res 2002, 68:615-621.

\section{doi:10.1186/1471-2415-14-165}

Cite this article as: Andjelić et al: Characterization of ex vivo cultured neuronal- and glial- like cells from human idiopathic epiretinal membranes. BMC Ophthalmology 2014 14:165.

\section{Submit your next manuscript to BioMed Central and take full advantage of:}

- Convenient online submission

- Thorough peer review

- No space constraints or color figure charges

- Immediate publication on acceptance

- Inclusion in PubMed, CAS, Scopus and Google Scholar

- Research which is freely available for redistribution 